\title{
Assessment of left ventricular apical rotation in obese by Cardiovascular MR tagging
}

\author{
Gabriella M Vincenti ${ }^{1 *}$, Jean-Noel Hyacinthe ${ }^{2}$, Joost PA Kuijer ${ }^{3}$, Francois Mach', Osman Ratib ${ }^{4}$, Thomas Schindler ${ }^{1}$, \\ Jean-Paul Vallée ${ }^{2}$
}

From 2011 SCMR/Euro CMR Joint Scientific Sessions

Nice, France. 3-6 February 2011

\section{Background}

Obesity is associated with cardiac remodelling with increased left ventricular mass and end-diastolic volume. CMR is a unique technique to evaluate cardiac morphology and function in obese individuals. Among CMR techniques, myocardial tagging allows to quantify myocardial strain and left ventricular rotation along the RR cycle (1). The aim of this preliminary study was to explore the feasibility of left ventricular apical rotation quantification by CMR tagging in obese individuals and exploring possible alteration of myocardial motion pattern.

\section{Methods}

8 healthy controls $(18<\mathrm{BMI}<25)$ were imaged using a $3 \mathrm{~T}$ trio system and 7 obese subjects $(B M I>30)$ without other cardiovascular risk factors and with normal left ventricular ejection fraction were imaged using a $1.5 \mathrm{~T}$ Espree system (wider bore, well adapted to obese subjects). We used an ECG gated, single breath hold balanced SSFP line tagging sequence with LISA, with CSPAMM acquisition scheme (2). The field of view was $340 \times 340 \mathrm{~mm}$, matrix 256 with $32 \%$ phase resolution, bandwidth $850 \mathrm{~Hz}$, slice thickness $7 \mathrm{~mm}$, tag spacing $7 \mathrm{~mm}$, TE 1.28 (TE 1.54@ $3 \mathrm{~T}$ ) and Flip angle $20^{\circ}\left(15^{\circ}\right.$ @ 3T). Images were analyzed and apical rotations were computed using Extrema Temporal Chaining (ETC) (3).

\section{Results}

The left ventricular apical systolic rotation measured by CMR tagging was increased and delayed in obese patients while the diastolic apical untwisting was prolonged, when compared to control subjects (Fig.1).

\footnotetext{
${ }^{1}$ Division of Cardiology, Geneva University Hospital, Geneva, Switzerland
} Full list of author information is available at the end of the article

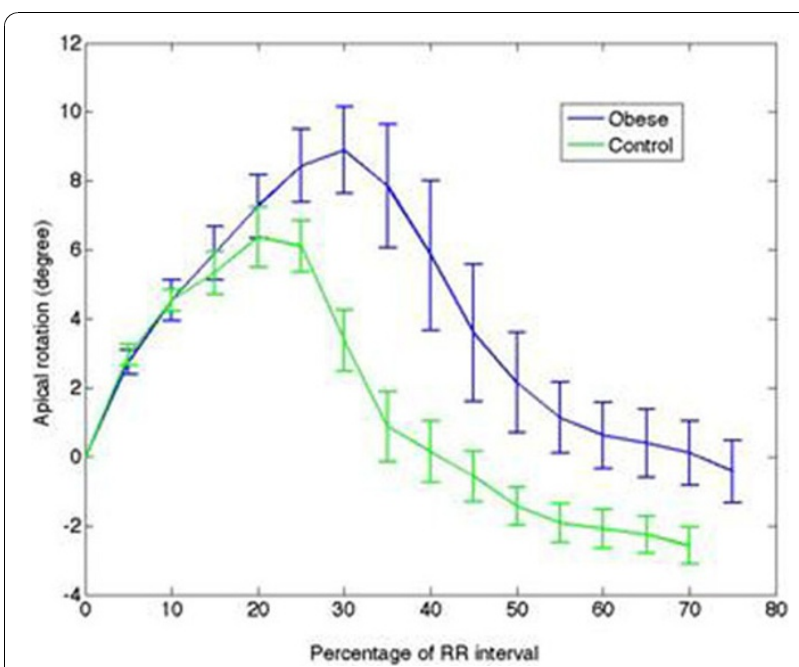

Figure 1 Left ventricular apical rotation along RR interval in Obese and control subjects.

\section{Conclusions}

Our preliminary results confirm the presence of an abnormal pattern of left ventricular rotation in obese individuals that can be identified with CMR tagging. This abnormal pattern may reflect the remodeling secondary to increased hemodynamic requirements (volume-overload and sympathetic system activation) in obese subjects, while the delayed diastolic untwisting may precede a diastolic dysfunction. These preliminary data confirm that CMR with myocardial tagging may allow identifying early abnormalities of left ventricular function in obese individuals with normal left ventricular ejection fraction. 
${ }^{3}$ Department of Physics \& Medical Technology, VU University Medical Center Amsterdam, Netherlands. ${ }^{4}$ Division of Nuclear Medecine, Geneva University

Hospital, Geneva, Switzerland.

Published: 2 February 2011

\section{References}

1. Stuber M, et al: Circulation 1999, 100(4):361-8.

2. Zwanenburg JJ, et al: Magn Reson Med 2003, 49(4):722-30.

3. Jacob JP: LNCS $2006,4179: 897-908$

doi:10.1186/1532-429X-13-S1-P326

Cite this article as: Vincenti et al:. Assessment of left ventricular apical

rotation in obese by Cardiovascular MR tagging. Journal of

Cardiovascular Magnetic Resonance 2011 13(Suppl 1):P326.

Submit your next manuscript to BioMed Central and take full advantage of:

- Convenient online submission

- Thorough peer review

- No space constraints or color figure charges

- Immediate publication on acceptance

- Inclusion in PubMed, CAS, Scopus and Google Scholar

- Research which is freely available for redistribution

Submit your manuscript at www.biomedcentral.com/submit
Ciomed Central 